\title{
AOR
}

Selected Papers of \#AolR2021:

The 22nd Annual Conference of the

Association of Internet Researchers

Virtual Event / 13-16 Oct 2021

\section{ENVIRONMENTAL INFLUENCERS ON INSTAGRAM: CONNECTIONS AND FRICTIONS BETWEEN ACTIVISM, LIFESTYLES AND CONSUMPTION.}

\author{
Gemma San Cornelio \\ Universitat Oberta de Catalunya \\ Elisenda Ardèvol \\ Universitat Oberta de Catalunya \\ Sandra Martorell \\ Universitat Politècnica de València
}

Environmental crisis is one of the main issues on the current social, political and media agenda that has spread to citizens engaging environmental activism in many ways. This paper focuses on the emergence of a very specific type of environmental activism in social media that we named as "eco-influencers". Drawing on our findings of an ongoing digital ethnography (Pink et al. 2016; Hjorth, Horst, Galloway, Bell, 2017) among Instagram profiles devoted to disseminate contents related to sustainability and climate change, our aim here is to explore some controversial issues regarding how they understand independence in relation to activism, lifestyle, consumption and work.

This form of digital activism promotes the idea of a sustainable lifestyle, based on that small daily actions may contribute to achieve global changes, and distancing itself both from traditional forms of environmental communication in mass media, and from social movements oriented towards protest and collective action in public space. Conversely, the so-named eco-influencers in Instagram focus on individual agency and domestic space as a place for political action. Moreover, they present a certain articulation with new ways of consumerism and an emerging market of sustainable products.

On the one hand, the connections between lifestyle and activism has been underestimated. Haenfler, Johnson and Jones (2012) contend that the separation between lifestyles and social movements has left a blind spot, located at the intersection between private individual action and activism, personal and social change, and personal and collective identity. They suggest the concept of Lifestyle Movements to point to social movements that actively promote new values and cultural meanings, challenging the hegemonic culture and fostering a broader social change through their

Suggested Citation (APA): San Cornelio, G; Ardèvol, E; Martorell, S. (2021, October). Environmental influencers on Instagram: connections and frictions between activism, lifestyles and consumption. Paper presented at AolR 2021: The 22nd Annual Conference of the Association of Internet Researchers. Virtual Event: AolR. Retrieved from http://spir.aoir.org. 
lifestyle. This kind of activism is based on three characteristics: lifestyle choices as a tactic for social change; the centrality of personal identity as the engine of change; and a diffuse organizational structure (Haenfler, Johnson and Jones, 2012: 2).

On the other hand, since our field of study is Instagram, we might consider the notion of visual activism for understanding the role of images and aesthetics in this digital activism. The most specific concept of visual activism is usually referred to artistic or creative groups, who put their visual and performative skills at the service of a cause. This type of activism has been negatively perceived by some authors since it is considered that the visual, as aesthetic, would lose strength to the movement (Demos 2006: 90). However, our argument is that precisely the potential of environmental activism on Instagram is articulated with the concept of consumption and lifestyle, involving personal narratives whose role of images is fundamental.

We named these environmental activist eco-influencers as these profiles develop similar strategies as those that, according to Leaver, Hihghfield and Abidin as influencers are characterized by: 1) applying positive self-branding strategies, 2) managing their visibility 3 ) cultivating their community of followers adopting storytelling techniques consistent with their lifestyles (Leaver, Hihghfield, Abidin, 2020: 106).

The fieldwork consists in participant observation in Instagram since July 2020 following the profiles through a collective research account to maintain interaction and expand our field site until we have an intentional sample of 60 profiles that allowed us to create a first typology and beginning in-depth interviews.

Coinciding with the categories of Shabir (2020) our sample is composed by: 1) lifestyle activists and bloggers, which, in turn, can be individuals, a couple, or family accounts dedicated exclusively to the environment and sustainable consumption; 2 ) influencers and lifestyle bloggers who also promote sustainable products; 3 ) accounts devoted to communicate tips, tricks and memes; generally managed individually or collectively and that are usually anonymous; 4) shops or small producers; 5 ) collectives and organizations, more focused on raising awareness and collective mobilization about the environment. For our study, we consider the first 4 categories as eco-influencers, although they would take part, as a whole, of an "ecosphere" in which environmental activism, ecological market and tips for a sustainable and healthy lifestyle are hybridized.

In this regard, the interviews have focused in the first 4 categories and we have interviewed 12 profiles ( 3 of each category). Here we highlight some features that have been raised regarding their activity as activists and the very notion of "eco-influencer". Firstly, we verify our initial perception that there is an emerging model of influencer coming from a familiar articulation. Families and couples engage in such projects of life changing (to more sustainable habits) and dissemination of it, as a way to compromise with their audiences.

All the interviewees claim that they are activists, but not interested in social movements and mobilisations on the street. They view themselves as independent agents interconnected through digital media, and their motivation is to change the world for 
better, educating the population through their own experiences, and in other cases, selling products that they have tested and match their ecological criteria. They try to live accordingly to their ideals about a sostenible life, respectful with the environment, and, if it is possible, as "influencers", also make a living becoming enterpreneaurs.

They are critical about consumerism, government environmental policies and the extractivist model of capitalism, but at the same time, they participate in the market, and they share the liberal belief of the individual as an independent agent, able to change society by an act of will. They consider the individual as an engine for social change, experiencing a heavy weight to carry individually, especially when trying to achieve an exemplary behaviour.

In terms of the limitations of their field of action, they express conflicting positions regarding Instagram, especially with the tyranny of its algorithm, expressing that they feel uncomfortable in a space out of their control. They are aware that they are not completely independent in this platform (indeed one of our interviewees that has left it).

These conflicting feelings are also present regarding the very definition of influencer, which they partially refuse due to its negative connotations. But on the other hand, they recognize their activity have a positive influence on their communities. Contrary to this, as we said, they all recognise being activists, although they offer nuances, such as their online activity is a specific way to change the world little by little, and that this is independent of being an activist in a classical way. In this regard, their use of visual resources is very accurate, since an important number of them have professional creative skills, and consider this may help to reach wider audiences.

These preliminary findings allow a characterization of a new mode of social activism with specific features. As activists, these 'eco-influencers' regard themselves as independent agents interconnected through digital media, contributing to produce a change in society through their own example. As independent creative workers, they face the contradictions of the need for visibility in order to spread their message and the constraints of the platforms they depend on. Independence is thus an aspiration as a way of life.

\section{References}

Demos, T.J. (2016). Between rebel creativity and reification: For and against visual activism. Journal of Visual Culture, 15(1), 85-102. https://doi.org/10.1177/1470412915619459

Haenfler, R., Johnson, B., \& Jones, E. (2012). Lifestyle movements: Exploring the intersection of lifestyle and social movements. Social Movement Studies, 11(1), 1-20. https://doi.org/10.1080/14742837.2012.640535

Hjorth, L., Horst, H., Galloway, A., \& Bell, G. (Eds.). (2017). The Routledge companion to digital ethnography. Taylor \& Francis. 
Leaver, T., Highfield, T., \& Abidin, C. (2020). Instagram: Visual social media cultures. John Wiley \& Sons.

Pink, S., Horst, H., Postill, J., Hjorth, L., Lewis, T., \& Tacchi, J. (2016). Digital ethnography: Principles and practice. Sage Pub.

Shabir, H. (2020). The representation of sustainability on social media: an ecofeminist reading of Instagram. Master Thesis Series in Environmental Studies and Sustainability Science. Lund University Centre of Sustainability Studies 